\title{
ESPECIALIZAÇAO EM PROJETOS ASSISTENCIAIS DE ENFERMAGEM: CONTRIBUIÇÕES NA PRÁTICA PROFISSIONAL DOS EGRESSOS ${ }^{1}$
}

\author{
Naiana Alves Oliveira², Maira Buss Thofehrn³, Diana Cecagno ${ }^{4}$, Hedi Crecencia Heckler de Siqueira ${ }^{5}$ \\ Adrize Rutz Porto
}

${ }^{1}$ Recorte do Trabalho de Conclusão de Curso (TCC) de Graduação - Contribuições do Curso de Especialização em Projetos Assistenciais de Enfermagem na prática profissional dos egressos. Faculdade de Enfermagem e Obstetrícia da Universidade Federal de Pelotas (UFPel), 2008.

${ }^{2}$ Mestranda do Programa de Pós-graduação em Enfermagem da Universidade Federal do Rio Grande (FURG). Técnico Administrativo da UFPel. Rio Grande do Sul, Brasil. E-mail: naivesoli77@ibest.com.br

${ }^{3}$ Doutora em Enfermagem. Professor Adjunto da Faculdade de Enfermagem e Obstetrícia da UFPel. Rio Grande do Sul, Brasil. Orientadora do TCC. E-mail: mairabt@hotmail.com

${ }^{4}$ Mestre em Enfermagem. Professor Assistente da Faculdade de Enfermagem e Obstetrícia da UFPel. Rio Grande do Sul, Brasil. Co-orientadora do TCC. E-mail: cecagnod@yahoo.com.br

${ }^{5}$ Doutora em Enfermagem. Professor do Programa de Pós-graduação em Enfermagem da FURG. Rio Grande do Sul, Brasil. E-mail: hedihs@terra.com.br

${ }^{6}$ Enfermeira. Rio Grande do Sul, Brasil. E-mail: adrizeporto@gmail.com

\begin{abstract}
RESUMO: Esta pesquisa do tipo descritivo-exploratório, com abordagem qualitativa, teve como objetivo conhecer as contribuições do Curso de Especialização em Projetos Assistenciais de Enfermagem da Faculdade de Enfermagem e Obstetrícia da Universidade Federal de Pelotas na prática profissional dos egressos. Os dados foram coletados através da técnica de grupo focal com a participação de 10 enfermeiros egressos do curso e tratados pela análise de conteúdo temática. O curso de Especialização em Projetos Assistenciais de Enfermagem permitiu aos egressos o entendimento sobre a prática do trabalho do enfermeiro. Foi evidenciado como fundamental para a construção do conhecimento do profissional em relação às práticas de assistência. Os enfermeiros egressos reconhecem a importância de participar de um curso de pós-graduação lato sensu, como forma de contribuição para a qualificação profissional e enriquecimento do conhecimento adquirido na prática assistencial.
\end{abstract}

DESCRITORES: Enfermagem. Especialidade. Prática profissional.

\section{SPECIALIZATION IN NURSING CARE PROJECTS: CONTRIBUTIONS IN PROFESSIONAL PRACTICE OF THOSE ENROLLED}

\begin{abstract}
This descriptive, exploratory study with a qualitative approach aimed to better understand the contributions of the Nursing Care Projects Specialization Course of the College of Nursing and Obstetrics, of the Federal University of Pelotas in the professional practice of those enrolled. The data were collected using the focus group technique, involving 10 nursing students from the course and treated with thematic content analysis. The Nursing Care Projects Specialization Course allowed better understanding of the nursing work practice for those enrolled. It was evidenced as fundamental for professional knowledge construction in relation to care practices. The enrolled nursing students recognize the importance of participating in a graduate course in lato sensu as a contribution to their professional qualification and enriching their knowledge of care practices.
\end{abstract}

DESCRIPTORS: Nursing. Specialism. Professional practice.

\section{ESPECIALIZACIÓN EN PROYECTOS ASISTENCIALES DE ENFERMERÍA: LAS CONTRIBUCIONES A LA PRÁCTICA PROFESIONAL DE LOS EGRESADOS}

\begin{abstract}
RESUMEN: Es una investigación descriptiva, exploratoria, con un enfoque cualitativo, cuyo objetivo fue conocer las contribuciones del Curso de Especialización en Proyectos Asistenciales de Enfermería de la Facultad de Enfermería y Obstetricia de la Universidad Federal de Pelotas, a la práctica profesional de los egresados. Los datos fueron recolectados a través de la técnica de grupo focal con la participación de 10 enfermeros egresados del curso y examinados por el análisis de contenido temático. El Curso de Especialización en Proyectos Asistenciales de Enfermería permitió a los egresados la comprensión sobre la práctica de la labor del enfermero. Se destacó como fundamental para la construcción de conocimientos profesionales en relación a la práctica de la asistencia. Los enfermeros egresados reconocen la importancia de participar en un curso de postgrado lato sensu, como una contribución a la calificación profesional y el enriquecimiento de los conocimientos en la práctica asistencial.
\end{abstract}

DESCRIPTORES: Enfermería. Especialización. Práctica profesional. 


\section{INTRODUÇÃO}

A qualificação profissional deve estar em conformidade e sintonia com os padrões de competitividade do mercado de trabalho, destacando que é imprescindível que os enfermeiros que atuam nos serviços de saúde estejam, constantemente, buscando um saber científico que subsidie a prática assistencial. ${ }^{1}$ Os cursos de pós-graduação lato sensu na área de enfermagem propõem ao profissional um preparo direcionado a uma área determinada do conhecimento com vistas a aprimorar a prática do cuidado ao cliente, usuário, família e comunidade.

A perspectiva do aperfeiçoamento do enfermeiro tem sido o foco para o trabalho em saúde, tanto para a satisfação do trabalhador como para assistência de qualidade aos usuários dos diversos sistemas de saúde. Nessa conjuntura, o curso de Especialização em Projetos Assistenciais (EPA) de Enfermagem objetiva criar oportunidade de reflexão acerca da realidade vivenciada profissionalmente na enfermagem. Além disso, busca auxiliar nas transformações da prática assistencial com a finalidade de promover esclarecimentos do próprio processo de trabalho no qual, os enfermeiros estão inseridos e estimular o conhecimento da relação e da importância da enfermagem.

O curso de EPA é oriundo de um esforço coletivo entre as seis universidades federais: Universidade Federal de Santa Catarina (UFSC), Universidade Federal do Paraná (UFPR), Universidade Federal de Santa Maria (UFSM), Universidade Federal de Pelotas (UFPel), Universidade Federal do Rio Grande (FURG) e Universidade Federal do Rio Grande do Sul (UFRGS), do sul do Brasil, que ao visarem o desenvolvimento da pós-graduação nessa região formaram a Rede de Pós-Graduação em Enfermagem da Região Sul (REPENSUL) em 1991 e posteriormente a Especialização em Enfermagem na Região Sul (ESPENSUL).

O curso de EPA iniciou na Faculdade de Enfermagem e Obstetrícia (FEO) da UFPel em setembro de 1996, tendo a carga horária de 630 horas. Tem como público-alvo os enfermeiros, que atuam nas instituições de saúde, públicas e privadas, caracteriza-se pelo ensino à distância, com modalidade semipresencial e pedagogia problematizadora fundamentada em Paulo Freire. O objetivo da EPA é desenvolver a competência de enfermeiros especialistas em projetos assistenciais comprometidos com resolutividade crítico-criativa nas práticas de cuidado de saúde de pessoas, grupos e comunidades, com ênfase na dimensão familiar. O curso se constitui de grupos de alunos, entre dois e três, o que permite o crescimento das relações interprofissionais, mediados por um(a) facilitador(a), além da participação de lideranças de instituições de saúde e de ensino, engajados na proposta do curso.

Para o desenvolvimento das atividades do curso de EPA, o material instrucional elaborado, como recurso pedagógico, foi a Série ESPENSUL, ou seja, uma série composta de livros, num conjunto de cinco, sistematizados especificamente para facilitar o processo de ensino-aprendizagem. Esta série, apresentada em cinco momentos curriculares, compreende textos de estudo de cada momento do processo de aprendizagem, explicitando os objetivos, os conteúdos, as atividades de aprendizagem e complementares, as perguntas para discussão, os resumos, bibliografias recomendadas e complementares, necessárias para o desenvolvimento do programa.

Ao final da especialização, os grupos de alunos elaboram e apresentam uma monografia, relatório da realização do projeto assistencial proposto, vinculado ao local onde desenvolvem suas atividades como enfermeiros. O processo de ensino-aprendizagem, por meio da transformação da realidade, estimula a busca pelo conhecimento, educação em saúde e a reflexão da prática profissional. Este relatório visa fornecer subsídios para que a FEO/UFPel, serviços de saúde e demais universidades de enfermagem, possam vislumbrar uma proposta de reformulação dos seus cursos de especialização, principalmente os voltados para a prática assistencial, além de tornar visível esta repercussão e a realidade posterior do curso.

Desta forma objetivamos conhecer as contribuições na prática profissional dos egressos do curso de EPA de Enfermagem da FEO/UFPel.

\section{A TRAJETÓRIA METODOLÓGICA}

A opção metodológica baseou-se em um estudo exploratório-descritivo, com abordagem qualitativa, realizado com os enfermeiros egressos do curso de especialização lato sensu de uma universidade federal do Sul do Rio Grande do Sul.

Os dados foram coletados durante os meses de setembro e outubro de 2008, junto aos enfermeiros egressos do curso de especialização. Os critérios para participação dos enfermeiros no estudo foram: ter participado da EPA de Enfermagem da FEO/UFPel, residir e trabalhar em Pelotas, consentir em participar do estudo, permitir que o 
estudo possa ser publicado em eventos e cadernos científicos, e assinar o Termo de Consentimento Livre e Esclarecido (TCLE). Participaram da pesquisa 10 enfermeiros, escolhidos aleatoriamente e que contemplaram os critérios para participação. Do total de enfermeiros egressos das cinco turmas do curso de EPA, três eram da primeira turma, dois da segunda turma, e cinco, da quinta turma. Os egressos da primeira turma concluíram a EPA em maio de 1998, a segunda turma, em março de 2000 e a quinta turma em março de 2008.

A coleta de dados deu-se por meio da técnica de grupo focal, a partir de uma questão norteadora, pois se entende que a dinâmica dos grupos focais oportuniza informações não de um indivíduo, mas de um grupo formado para um período destinado à coleta de dados, reunidos em torno de um interesse relacionado ao tema da investigação. ${ }^{2}$ A questão norteadora do estudo ficou assim constituída: quais as contribuições do curso de EPA de Enfermagem na prática profissional dos egressos. Para o cumprimento ao anonimato, garantido aos sujeitos do estudo, lhes foram dados nomes fictícios, escolhidos pelos próprios participantes. A identificação dos sujeitos, para melhor compreensão temporal, foi descrito da seguinte maneira: o nome fictício acrescido do número correspondente a sua turma no curso de EPA.

Os participantes foram reunidos em dois grupos focais distintos, com duração de duas horas cada, num total de cinco participantes em cada um dos encontros. Os encontros ocorreram numa sala de aula, na FEO/UFPel, sob a coordenação da pesquisadora. Além da coordenação, o grupo focal contou com a presença de duas observadoras, alunas da graduação em enfermagem. No contexto do grupo focal, essa técnica para a coleta de dados permite a apreensão dos fenômenos existentes, demonstrando aspectos incertos que emergem a partir do momento em que um grupo é reunido. ${ }^{3}$

O protocolo de pesquisa foi aprovado pelo Comitê de Ética em Pesquisa da Santa Casa de Misericórdia de Pelotas, sob protocolo No 039/ 2008. Todos os aspectos que envolvem a pesquisa estão de acordo com a Resolução No 196/96 do Conselho Nacional de Saúde do Ministério da Saúde 4 e o Código de Ética dos Profissionais de Enfermagem de 2007, ${ }^{5}$ sendo que as participantes assinaram o TCLE.

Os depoimentos obtidos foram gravados, transcritos e editados. A análise foi realizada com base no método da análise de conteúdo temática, ${ }^{6}$ no qual emergiram os seguintes temas: o curso de EPA na vida profissional do egresso; envolvimento das instituições de saúde na formação do profissional enfermeiro; e repercussões do curso de EPA na prática assistencial do enfermeiro.

\section{RESULTADOS E DISCUSSÕES}

\section{O curso de EPA na vida profissional do egresso}

A respeito da contribuição do curso de EPA na vida profissional dos egressos, alguns enfermeiros demonstraram que o curso propiciou rever a importância da integralidade do cuidado.

[...] a questão das especialidades [...] eu não agüento mais as "caixinhas", inclusive das profissões. Hoje não importa mais se tu és enfermeiro, médico, psicólogo ou assistente social. Não é a especialidade que vai garantir [...] a integralidade do cuidado [...] Tu tens que ser capaz de cuidar de alguém que está precisando (Apaixonada 1).

A prática interdisciplinar, que representa um atendimento cooperativo, participativo, com diálogo aberto e igualitário, ${ }^{7}$ coloca-se como exigência confrontando com a prática atual, extremamente fragmentada, como citou a participante do grupo ao utilizar o termo "as caixinhas".

Nesse contexto, a necessidade de integralidade do cuidado tem caracterizado uma preocupação entre os profissionais enfermeiros, reforçando a necessidade de ações profissionais conjuntas para o atendimento em saúde, independente da categoria de trabalhador em saúde. Como consequência das especializações por área específica do conhecimento, os quais propiciaram por um todo o avanço tecnológico nunca antes vislumbrado, por outro lado houve um distanciamento da visão holística, do conhecimento que é adquirido pelo ser humano, o que configura num aspecto em que a EPA atende e complementa já que o especialista adapta a prática do projeto assistencial as mais diferentes realidades e desenvolve suas ações a partir da identificação de um problema ou de uma dificuldade.

[...] a questão do ser especialista [...] existe hoje todo um movimento no sistema de saúde, na formação [...] que tu especializes alguém em pediatria, alguém nisso, alguém naquilo outro [...] a amplitude de tu te especializares, a capacidade de problematizar, em qualquer situação, e ser capaz de fazer um projeto de intervenção, é muito mais válida do que a especialização numa área temática qualquer da saúde (Apaixonada 1). 
Ressaltamos que o estudo compartimentado contribui de modo significativo para o aprimoramento e aprofundamento do conhecimento de áreas específicas. Mas, somente essa realidade não contempla mais a necessidade de saúde da coletividade e da integralidade, desta forma, existe um movimento de resgate da visão sistêmica com ênfase na complexidade do ser humano.

Uma enfermeira referiu que na prática profissional ainda são valorizadas as ações tecnicistas, pois a formação era voltada para essas questões. Atualmente, além da competência técnica, a enfermagem busca consolidar-se enquanto ciência, baseada no cuidado humano.

[...] a gente tinha ou tra formação, a gente queria ser tecnicista assistencial, a gente queria ser o melhor, a gente queria ser o melhor a passar sonda, a gente queria sair no escuro e acertar sonda na uretra de todo mundo [...] era uma coisa meio sem sentido (Amorperfeito 1).

O exposto nos conduziu a perceber que "o trabalho, em seu sentido de produção de bens úteis materiais e simbólicos, é condição constitutiva da vida dos seres humanos em relação com outros seres humanos", ${ }^{8: 97}$ e a enfermagem alcançou um momento em que não basta somente o saber-fazer da prática assistencial, é necessário um saber-fazer com orientação científica e teórica, aspectos que sustentam o próprio cuidar.

A contribuição de impacto do curso está atrelada às questões que envolvem as políticas públicas de saúde já que essas devem fazer parte do todo nos serviços de saúde e por muito tempo esteve ligado somente aos profissionais de saúde da área comunitária. Os participantes relataram experiências positivas e marcantes em relação à oportunidade que tiveram de estudar o contexto das políticas públicas na especialização.

Uma coisa que me marcou muito [...] Sistema Único de Saúde, eu me lembro de um exercício que tu tinha que entrevistar gestor [...] isso pra mim foi bastante útil, por que hoje eu trabalho com gestão [...] foi uma das coisas que me marcou [...] foi ter aprofundado o conhecimento na lei orgânica da saúde e do sistema único de saúde (Apaixonada 1).

Diante do exposto, pudemos constatar que a formação de especialista em EPA está além da formação tecnicista assistencial, pois muitos dos enfermeiros egressos tiveram a oportunidade de aprofundar seu conhecimento acerca do Sistema Único de Saúde (SUS). Por outro lado, os profissionais que trabalhavam na atenção primária, referiram que o curso de EPA possibilitou uma melhor articulação do conteúdo teórico com a vivência prática, desmistificando e reforçando a necessidade da adequação de todos os profissionais a esse modelo de saúde.

Eu não acreditava no Sistema Único de Saúde, apesar de ter ido trabalhar nele. Eu comecei a acreditar com aquelas aulas de toda a história do sistema de saúde do Brasil [...] E isso até hoje, por que a gente tem uma proposta muito boa e acho que essa proposta só não vai adiante por que muitas pessoas não acreditam nela (Vida 1).

[...] à medida que tu te aproprias realmente desse conhecimento do que éo SUS, como funciona, por queé daquele jeito, por que não é diferente, a gente consegue até melhorar (Princesa 5).

Essas falas mostram claramente, alguma desacreditação quanto ao modelo de atenção à saúde, quando dizem que é um sistema em que "não acreditavam" que "muitas pessoas não acreditavam" e que pode "até melhorar". Após estas constatações, ao conhecermos algo novo, ainda desconhecido, o medo e a insegurança desencadeiam sentimentos de abandono e de ansiedade o que interfere significativamente em qualquer mudança que seja proposta no contexto do trabalho. ${ }^{9}$ Nessa conjuntura, a resistência à mudança, característica do ser humano, vai ao encontro dessas limitações individuais provocando muitas vezes a falta de estímulo para apoiar uma idéia, uma proposta, por que retira o trabalhador da sua área de domínio e comodidade.

Estamos vivendo um momento de complexas mudanças no contexto da qualificação profissional. A partir disso, verificamos que a inquietação dos profissionais quanto a se sentirem afastados do conhecimento teórico e científico, ainda é uma preocupação. Percebemos ainda, que de alguma forma, eles sentem-se aprisionados à prática assistencial, tecnicista, do "fazer e fazer", e consideram a importância da especialização como forma de libertá-los e aproximá-los desse "novo aprender" que estava enfraquecido.

[...] hoje em dia eu sou atuante dentro do conselho de saúde [...] se eu nunca tivesse feito a especialização, e se eu ficasse trabalhando e não quisesse ler mais nada a respeito [...] ficamos alienados (Princesa 5).

[...] a coisa não é só trabalhar, tem que estudar, procurar ler muito para poder adquirir coisas para a unidade (Jasmin 2).

A alienação é uma das principais características do mundo moderno, em que o ser humano 
passa a questionar a sua própria história, seus próprios limites e verdades. ${ }^{10}$ Nesse sentido, os questionamentos do enfermeiro enquanto profissional da saúde, torna-se um sofrimento, em decorrência da própria carência do sistema de saúde. Desta forma, a qualificação profissional deve estar constantemente inserida na formação do profissional enfermeiro, a fim de proporcionarlhe o encontro de seus potenciais, e nos atrevemos a dizer também, que especializar-se é expandir as ações do enfermeiro o que ocasiona um trabalho mais prazeroso, mais digno e mais autêntico.

[...] a gente dava valor em fazer o projeto pra modificar a nossa realidade de trabalho [...] na época, a nossa curiosidade, a nossa vontade, era modificar a prática, era tentar ter uma visão ampliada (Vida 1).

Para mim contribuiu bastante [...] eu achava que fazia um bom trabalho voltado para o paciente, mas depois que comecei a ler [...] a especialização serviu para dar um 'sacode' (Jasmin 2).

De acordo com o exposto, além de permitir mudança e ampliar a visão sobre o trabalho assistencial, o curso de EPA auxiliou aos egressos a visualização de uma prática muitas vezes estagnada, desamparada e vazia de conhecimentos científicos. A oportunidade de realizar esta especialização, possibilitou incrementar a vida profissional, permitindo também a compreensão do crescimento enquanto uma pessoa singular e com potencial de mudança.

A especialização pra mim além de crescimento profissional excelente [...] a gente volta estudar, a rever pessoas e colegas [...] tu revê muita coisa que tinha esquecido [...] as teorias foram vistas, deu para rever isso mais especificado, foi bem comentado, bem estudado [...] não me lembrava mais (Flor 5).

[...] pra mim foi bem importante [...] por que mudou completamente o modo de pensa (Vida 1).

[...] a gente conseguiu transportar aquilo pro dia-a-dia da gente, aquele método, aquela maneira de pensar [...] (Princesa 5).

Um dos aspectos importantes a ser mencionado foi a releitura da enfermeira frente ao cuidado da família, preocupação conquistada durante o curso de EPA e que faz parte do seu processo de cuidado até hoje.

[...] tu começas avaliar diferente a família [temática trabalhada na $5^{\text {a }}$. turma] [...] na abordagem deles, tu interpreta diferente, aproveitando a teoria [...]. Pra mim então a especialização valeu, continua valendo, continuo aplicando o que aprendi no meu projeto, em especial, nos locais onde trabalho, com as pessoas que eu trabalho (Flor 5).
A compreensão do cuidado familiar "propicia aos profissionais de saúde elementos significativos para reflexão e para seu agir profissional" ${ }^{11: 25}$ Esses elementos, de acordo com as autoras envolvem responsabilidade e compromisso que devem estar direcionados para o fortalecimento, apoio e orientação do sistema familiar quando essa se apresentar fragilizada. Pudemos constatar que o curso de EPA contribuiu no enriquecimento do compreender o processo de cuidado às famílias.

Além, de crescimento profissional para a prática assistencial, alguns enfermeiros egressos do curso de EPA, tiveram a oportunidade de construir um processo de aprendizado que oferecesse condições para ingressarem em outro curso de pós-graduação, no caso, o mestrado.

[...] ela [EPA] no mestrado está me ajudando um monte [...] veio ao encontro do que eu vou trabalhar agora (Estrela 5).

[...] contribuiu bastante [...] e para quem fez especialização deu outra noção do mestrado (Jasmin 2).

\section{Envolvimento das instituições de saúde na formação do profissional enfermeiro}

Considerando o envolvimento das instituições de saúde, colaboradoras no processo de formação dos egressos do curso de EPA, grande parte das participantes apresentou as instituições como facilitadoras nesse processo, da construção do conhecimento, apresentando um perfil satisfatório de comprometimento com o seu profissional. Nessa perspectiva, consideramos como aspectos importantes para a qualidade de vida no trabalho a formação e qualificação profissionais.

[...] a gente tinha que levar o projeto para dentro do hospital [...] levar pra apresentar para o administrador do hospital e para a equipe que a gente trabalhava (Vida 1).

[...] proporcionava espaço, ambiente físico, apresentações dos trabalhos [...] eles apoiaram o pessoal, eu recebia apoio mesmo [...] eu não tive liberação por que eu trabalhava à tarde [...] mas em todos os outros sentidos, eles apoiavam [...] eu trabalhei dentro da minha própria unidade, no meu horário de trabalho, eles já me conheciam [...] (Comigo-ninguém-pode 2).

Ao atender as necessidades dos trabalhadores, incluídas aqui, a capacitação e aprimoramento do saber-fazer, a instituição está promovendo um ambiente de trabalho humanizado, já que encoraja e estimula os profissionais a desenvolver suas aptidões. $\mathrm{O}$ investimento na qualidade de vida 
no trabalho motiva o profissional para a identificação de situações problemas, e de contextos que precisam ser alterados, modificados ${ }^{12}$ de modo a prestar um cuidado adequado e efetivo.

Teve um caso que se repetiu [...] a equipe de saúde não tinha feito intervenção nenhuma naquela família. Aquela família, sem apoio, sem vínculo com o serviço de saúde [...] não teve suporte nenhum [...] isso mostrou um momento falho [...] a gente vai lá, cumpre um papelzinho certinho, mas cadê o apoio a família? Então foi bem legal em relação a isso, da gente ver, poder vivenciar algo que precisava ser mudado (Estrela 5).

Em toda a instituição de saúde, como em qualquer organização de trabalho, a motivação, favorece o desempenho de seus trabalhadores, encoraja o crescimento e a auto-realização e tudo isso vai gerar impacto no enriquecimento do seu papel social e de participante nos processos de melhoria da instituição em que trabalha. A partir disso, constatamos, que o curso de EPA foi satisfatório também nesse sentido do trabalhador conquistar um espaço na instituição.

[...] reflete em todo o meu trabalho, porque mudou toda a filosofia [...] do lugar que mais gosto de trabalhar que é a UTI Pediátrica [...] e hoje tem a entrada dos pais em qualquer horário, permanência, estimulação ao aleitamento materno [...] agora tem a pousada, então foi bem bom (Amor-perfeito 1).

[...] a gente contribuiu bastante naquela época [...] a gente sugeriu na época [...] a educação continuada porque a humanização provocou inicialmente assistência ao cliente, mas conforme foi andando o trabalho, a gente viu que a equipe de enfermagem era muito importante (Jasmin 2).

Ainda refletindo sobre o exposto, constatamos também que a proposta do curso de EPA, no que se refere à construção de um conhecimento baseado numa filosofia transformadora, os egressos mostraram, em sua maioria, que se tornaram "consciente, captador, apreendedor, transformador, criador de beleza e não 'espaço' vazio a ser enchido por conteúdos". ${ }^{13: 22}$

Contudo, uma significativa parte dos participantes relatou que não tiveram apoio da instituição de saúde para realizarem o curso de pósgraduação lato sensu, principalmente em relação a liberação de carga horária.

[...] naquela época como eu já tinha uma especialização [...] muitos enfermeiros se candidatando, as outras enfermeiras foram dispensadas da instituição para especialização, e eu não, então eu tinha que jogar com folgas (Comigo-ninguém-pode 2).
[...] a especialização quando fiz [...] nós não tivemos liberação [...] foi frustrante essa falta de apoio das instituições, porque na hora de dizer, "vamos dar apoio" [...] isso é muito fácil, agora realmente efetivar isso é complicado (Amor-perfeito 1).

[...] as minhas colegas de grupo, todas, era um sofrimento para conseguir [dispensa da instituição] [...] as duas trabalhavam na mesma instituição e uma cobria a outra, e aí dez anos depois continua o mesmo pensamento nas instituições, a mesma dificuldade do pessoal conseguir, se liberar e participar (Violeta 5).

Alguns elementos são importantes para as relações de trabalho, entre eles, a valorização do sujeito trabalhador e a consideração para com as emoções e sentimentos presentes nas relações interpessoais. ${ }^{14}$ Reconhecer a importância desses aspectos na organização hospitalar favorece ações mais participativas e compartilhadas entre gerentes e equipes, o que implica em refletir sobre o trabalho, sobre oportunizar a qualificação dos seus profissionais, e a garantia de proporciona-lhes condições para tal.

Uma atitude de desacreditação de um participante da equipe de trabalho pode implicar no impedimento da implementação de uma mudança assistencial e consiste num tipo de resistência ${ }^{12}$ apresentado pelos funcionários de uma instituição, no qual participa um dos sujeitos deste estudo.

Foi muito difícil [desenvolver a pesquisa] dentro da UTI, a maior dificuldade foi com os colegas, com o pessoal da enfermagem [...] (Vida 1).

Refletindo ainda sobre a resistência ao novo, ao desconhecido, acreditamos que os trabalhadores tendem a resistir às mudanças "devido ao custo psíquico que as acompanham". ${ }^{12: 43}$ Dentre esses "custos psíquicos" consideramos que a insegurança e o medo do novo ilustram o comportamento desses profissionais afetando diretamente o crescimento da instituição como um todo.

\section{Repercussões do curso de EPA na prática assistencial do enfermeiro}

Em relação à prática profissional, uma das falas relatou que a atuação do enfermeiro está voltada essencialmente para a assistência no cumprimento de tarefas como demonstrado a seguir.

[...] fazíamos todas as atividades só que não pensávamos, só trabalhava, tarefa e tarefa [...] eu acho que melhorei muito [...] a partir da especialização [...] vou poder seguir trabalhando as teorias [...] (Violeta 5).

A tarefa de cuidar representa um dos pressupostos do trabalho da enfermagem, atuando como 
um dos principais componentes organizacionais do trabalho e da equipe, pois "representa o processo de aprender a pensar, em termos da resolução das dificuldades manifestadas" .978 Portanto, o cuidado é essencial, pois oportuniza a reflexão da práxis diária.

[...] acho que a gente tem que realmente estar inteiro nesse processo de aprendizado, de incorporar essa troca entre a teoria e a prática, procurar levar essa teoria para a prática, e eu acho que o curso [...] foi um despertar (Vida 1).

Essa forma de educação preconizada pela EPA vai ao encontro de "uma prática transformadora, que seja capaz de provocar a convergência entre a transformação individual e a transformação social" ${ }^{15: 418}$ Pudemos constatar que, diante o exposto, a especialização motivou o profissional na produção de mudanças no contexto do seu trabalho, favorecendo um crescimento individual e coletivo.

[...] a interação com a mãe [de crianças internada na UTI pediátrica] [...] mexeu muito, foi um processo de mudança. E foi quando me despertou pra coisa da humanização (Vida 1).

A produção científica nos cursos de pósgraduação constitui um conhecimento adquirido a ser valorizado e respeitado. Os alunos pós-graduandos, por comumente não estarem habituados, em sua maioria, a produzir trabalhos científicos na graduação, apresentaram dificuldades no momento em que precisaram se dedicar ao curso de especialização.

Alguns participantes, ao comentarem sobre a produção científica durante a realização do curso de EPA, referiram que a especialização contribuiu no sentido de dinamizar e socializar o conhecimento adquirido nesse Curso, não somente para o meio acadêmico e científico, mas, principalmente, dividir esse aprendizado no seu local de trabalho.

[...] para mim é oportunidade de estudar [...] produção científica é resultado [...] eu acho extremamente importante produção científica no sentido de ser instrumento de socialização, de troca [...] eu acho que eu produzi muito a partir daquela especialização sem estar dentro da academia, em outros momentos, em outros espaços, principalmente no trabalho que é onde eu acho que é mais importante ter produção científica [...] (Apaixonada 1).

E acho isso bem legal [produção científica] na medida em que tu vai poder, usando um termo que já foi colocado, socializar tua experiência de poder modificar tua prática através de uma teoria (Girassol 5).
Por outro lado, a maioria dos egressos do curso de EPA considera importante a exposição dos seus trabalhos monográficos produzidos durante a pós-graduação para o meio científico, pois os consideram úteis para a construção do conhecimento para outros profissionais, além de instigar a pesquisa em outras pessoas.

A gente acaba coletando, trabalhando [...] então pode ser uma experiência legal que outra pessoa vai reproduzir [...] eu acho legal a gente divulgar o trabalho [...] alguém vai ler, vai achar que "eu posso fazer isso também" é nesse sentido que eu acho legal (Estrela 5).

Eu achei isso positivo na nossa turma, a gente já sabia que no final ia transformar um artigo, e não foi preocupante por que igual tu ia concluir, dali era só transformar num artigo (Girassol 5).

[...] nós encaminhamos agora para publicar um artigo, está para ser publicado, então acrescentou nisso também (Flor 5).

Outro aspecto significativo abordado pelos participantes foi que o processo de aprendizado no curso de EPA não foi apenas cognitivo, mas também resultou em atitudes e movimentos que envolveram a participação da instituição de ensino, professores, e, principalmente, os alunos, na aquisição de valores e de conhecimentos teóricos, os quais consideram importantes para a construção do conhecimento dentro da academia.

[...] agora a gente quer tentar colocar [as teorias de enfermagem] dentro do quarto semestre [...] dando uma orientação, tentando relacionar a prática profissional com a teoria (Violeta 5).

[...] era novo [o curso de EPA] para os professores, na realidade não era só nós estudando, eram as professoras também aprendendo (Amor-perfeito 1).

A vivência profissional dos alunos egressos do curso de EPA tem mostrado que as teorias de enfermagem foram conhecidas pelos alunos na pós-graduação e reconhecem a necessidade de introduzir as teóricas ainda na graduação com maior ênfase e relacionando, desde já, com a prática profissional. Essa busca pelo conhecimento e reflexão sobre a prática profissional torna o aluno mais crítico e reflexivo, oportunizando o desenvolvimento de condutas que visam a melhoria da qualidade da assistência prestada. ${ }^{16}$

\section{CONSIDERAÇÕES FINAIS}

Considerando que o curso de EPA atende à proposta de inserção do enfermeiro na prática assistencial, oportunizando o desenvolvimento 
das atividades do curso no próprio ambiente de trabalho, pode-se dizer que este estudo atingiu seu objetivo.

Através dos resultados, é possível dizer que na vida profissional do enfermeiro, o curso de EPA contribuiu para a qualificação e aperfeiçoamento da equipe e do ambiente de trabalho. Além disso, visualiza-se a importância dos desencadeamentos de processos de mudança na forma de ver e de atuar da enfermagem. Alguns dos participantes salientaram a importância de construir um processo de aprendizado que possa contribuir para o seu ingresso em outro curso de pós-graduação.

As instituições de saúde, quando envolvidas com a qualificação dos profissionais, podem ser facilitadoras do processo, atuando de forma colaborativa e comprometida. Quando isso não ocorre, a presença do descomprometimento com o ser trabalhador inibe formas de proporcionar condições e enriquecimento para o crescimento enquanto profissional de enfermagem, as quais a coordenação do curso se coloca à disposição dos alunos para auxiliar no processo de negociação.

Por fim, o curso de EPA contribuiu para o crescimento profissional do enfermeiro, dinamizando o conhecimento adquirido no meio acadêmico, tornando-o capaz de socializar esse conhecimento no contex to do trabalho e nos meios científicos. Destaca-se que a EPA de Enfermagem está passando por um processo de reformulação de sua proposta teórico-metodológica e que um grupo de professores da FEO da UFPEL está engajado na retomada de uma especialização que vise à continuidade dos estudos do profissional enfermeiro que atua na assistência.

\section{REFERÊNCIAS}

1. Lange C, Bielemann VM, Meincke SMK, Thofehrn MB, Schwartz E. Negociação: um dos pilares no programa de ensino à distância. Texto Contexto Enferm. 1999 Jan-Abr; 8(Esp):35-43.

2. Leopardi MT, Beck CLC, Nietsche EA, Gonzáles RMB. Metodologia da pesquisa na saúde. Santa Maria (RS): Pallotti; 2001.

3. Bunchaft AF, Gondim SMG. Grupos focais na investigação qualitativa daidentidadeorganizacional: exemplo de aplicação. Estud Psicol (Campinas). 2004 Mai-Ago; 21(2):63-77.

4. Ministério da Saúde (BR), Conselho Nacional de Saúde, Comissão Nacional de Ética em Pesquisa. Resolução No 196 de 10 de outubro de 1996: diretrizes e normas regulamentadoras de pesquisa envolvendo seres humanos. Brasília (DF): MS; 1996.

5. Conselho Federal de Enfermagem. Código de Ética dos Profissionais de Enfermagem. Resolução 311/207, de 08 de fevereiro de 2007. Rio de Janeiro (RJ): COFEN; 2007.

6. Minayo MCS. O desafio do conhecimento: pesquisa qualitativa em saúde. São Paulo (SP): Hucitec; 2004.

7. Tavares CMA, Matos E, Gonçalves L. Grupo multiprofissional de atendimento ao diabético: uma perspectiva de atenção interdisciplinar à saúde. Texto Contexto Enferm. 2005 Abr-Jun; 14(2):213-21.

8. Frigotto G. A produção social da existência: base dos processos de ensinar e aprender. Cadernos Educação FaE/UFPel. 2003 Jan-Jun; 12(20):94-104.

9. Pichon-Rivière E. O processo grupal. $7^{\mathrm{a}}$ ed. São Paulo (SP): Martins Fontes; 2005.

10. Arendt H. A condição humana. $8^{\mathrm{a}}$ ed. Rio de Janeiro (RJ): Forense Universitária; 1997.

11. Elsen I. Cuidado familial: uma proposta inicial de sistematização conceitual. In: Elsen I, Marcon SS, Silva MRS, organizadores. O viver em família e sua interface com a saúde e a doença. $2^{\mathrm{a}}$ ed. Maringá (PR): EDUEM; 2004. p.19-28.

12. Davis K, Newstrom JW. Comportamento humano no trabalho: uma abordagem organizacional. São Paulo (SP): Pioneira Thomson Learning; 2001.

13. Freire P. Pedagogia da autonomia. $29^{a}$ ed. São Paulo (SP): Paz e Terra; 2004.

14. Kurcgant P, Massarollo MCB. Cultura e poder nas organizações de saúde. In: Kurcgant $P$, organizador. Gerenciamento em enfermagem. Rio de Janeiro (RJ): Guanabara Koogan; 2005. p. 26-36.

15. Prado ML, Dias LPM, Silva DMGV, Fontoura MH. Desenvolvimento de tecnologia de educação à distância para cursos de Especialização em Enfermagem. Texto Contexto Enferm. 1999 Jan-Abr; 8(1):417-28.

16. Cecagno S, Santana MG, Thofehrn MB, Cecagno D. Ensino a distância: um meio para capacitação do(a) enfermeiro(a) no trabalho. Cadernos Educação Fae/ UFPel. 2003 Jan-Jun; 12(20):193-9. 